\title{
Development and Formulation of an Organic Fertilizer from Industrial and Agricultural Waste to Study the Growth of Marigold (Tagetes) Plant
}

\author{
Subhasish Majee \\ Department of Chemical Engineering, \\ National Institute of Technology Durgapur, West Bengal, 713209, India. \\ E-mail: subhasish.prochem@gmail.com \\ Gopinath Halder \\ Department of Chemical Engineering, \\ National Institute of Technology Durgapur, West Bengal, 713209, India. \\ E-mail: gopinath_haldar@yahoo.co.in

\section{R. N. Krishnaraj} \\ Department of Chemical and Biological Engineering, \\ South Dakota School of Mines and Technology, Rapid City, SD, USA. \\ E-mail: Navanietha.Rathinam@sdsmt.edu

\section{Tamal Mandal} \\ Department of Chemical Engineering, \\ National Institute of Technology Durgapur, West Bengal, 713209, India. \\ Corresponding author: prof.tamalmandal@gmail.com
}

(Received February 15, 2019; Accepted February 16, 2020)

\begin{abstract}
The present study focused on the utilization of solid wastes viz. wet blue leather of leather industry, rice husk ash from rice mills, and water hyacinth in addition to a commercial steamed bone meal for the invention of nutrient-enriched organic fertilizer. To produce NPK organic fertilizer, chromium-free wet blue leather (WBL) as nitrogen source was amalgamated with rice husk ash, water hyacinth, and commercial steamed bone meal as a potassium and phosphorus source. The efficiency of such developed organic fertilizer designated as type I was tested as a nutrients source on the marigold plant. Ammonia analysis of fertilizer applied soil samples revealed that the content of liberated free ammonia in the soil fertilized with organic fertilizer was $44.80 \%, 20.70 \%$, and $10.35 \%$ higher than the natural soil, chemically fertilized soil and fertilized with vermicompost respectively. Application of developed organic fertilizer and vermicompost designated as type II on marigold plant resulted in significant growth which are comparable to those obtained with commercial Chemical fertilizer. The plant growth increased by chemical fertilizer, Type I fertilizer, and Type II fertilizer in terms of plant height $26.5 \%, 20 \%, 22.7 \%$ and leaf size $21.2 \%, 15.4 \%, 17.3 \%$ respectively which are observed to be higher than the growth of the control plant.
\end{abstract}

Keywords- Wet blue leather, Rice husk ash, Organic fertilizer, Vermicompost, Plant growth.

\section{Introduction}

Continuous apply of chemical fertilizers, showing negative impact on the soil environment. Long exposure of such chemical fertilizer gives a deleterious effect on soil characteristics and fertility (Shimbo et al., 2001). Need enhancing organic inputs to reduce weakening soil quality of the agricultural field (Kochakinezhad et al., 2012). To overcome this problem, people are trying to develop organic fertilizer, which can be used as an alternative to chemical fertilizer (Nogueira et 
al., 2010). Organic fertilizer is getting importance due to its controlled release tendency to give proper nutrition to the plant and reduces the labor cost (Itelima et al., 2018). It also helps to restrict the growth of other unwanted species in the field of application. The leather industrial solid wastes (wet blue leather) containing a high amount of chromium. Due to the high cost involved in the chromium removal process, most of the small leather tanning industries do not properly discard their rejected parts in the environment (Oliveira et al., 2007). Nevertheless, an average amount of $140 \mathrm{~g} / \mathrm{kg}$ of nitrogen (dry weight) present in wet blue leather (WBL) (Nogueira et al., 2011). The reported work in the literature is suggesting that after chromium elimination, this can be utilized as nitrogen-enriched organic fertilizer and a suitable substitute for their safe disposal with a minimum potential impact on humans and also on the environment. Rice husk ash considered as waste material from the rice mill industry can cause environmental (air pollution) and human healthrelated problems (Pode, 2016). Rice husk ash and water hyacinth ash both are phosphorus and potassium-rich organic source which can be used as fertilizer for better plant growth (Masaka and Ndhlovu, 2007; Priyadharshini and Seran, 2009). Many reported works have demonstrated that bone meal is the fast releasing phosphorous source, it can enhance the plant growth (Nimje and Potkile, 1997). Reutilization of waste of industries can prevent environmental pollution and at the same time, this can accomplish the requirements of macro and micronutrients to agriculture by developing organic fertilizer (Han et al., 2016). In the present study, formulation has been made for the development of an organic fertilizer production using nitrogenous collagenic material (after chromium removal from WBL), available other low-cost potassium-rich ingredients viz. rice husk ash and water hyacinth ash in addition with phosphorus enriched commercial steamed bone meal as a source of plant nutrients (Lima et al., 2010). To evaluate the efficacy of this formulated fertilizer has been studied on the marigold (Tagetes) plant.

\section{Materials and Method}

The WBL solid waste was supplied by Leder Chemische Private Limited located at Tangra, Kolkata-15, India, agricultural waste rice husk ash (RHA) from Bhabatarini Rice Mill (Bankura more, Purba Bardhaman, West Bengal), and Water hyacinth from the nearest pond of Bathan, Raghunathpur, Purulia, West Bengal, India. Required chemicals like $\mathrm{HCL}, \mathrm{NaOH}, \mathrm{H}_{2} \mathrm{O}_{2}, \mathrm{H}_{2} \mathrm{SO}_{4}$, etc. were purchased from Merck Specialities Private Limited. Steamed bone meal powder was purchased from Anjaneya coco pith products located at Dindugul road, Vathalagundu, Dindigul, Tamil Nadu, India. Healthy marigold plants were purchased from the nursery, located at Benachity, Durgapur, India.

\subsection{Chromium Removal of WBL Waste by Alkali and Acid Treatment}

The alkali and acid treatment was performed to remove the chromium from WBL waste. In alkali treatment, 3 grams of WBL waste was immersed into $100 \mathrm{ml}$ of $1 \mathrm{~N} \mathrm{NaOH}$ solution for 60 minutes. The collagenic material (Oliveira et al., 2008) was filtered out from the chromium extracted $\mathrm{NaOH}$ solution. The collagenic material was washed with distilled water for two times to remove unwanted chromium and chemicals. After completion of alkali treatment, $\mathrm{H}_{2} \mathrm{O}_{2}$ treatment was performed by submerging the collagenic material in $3 \% \mathrm{H}_{2} \mathrm{O}_{2}$ for 30 minutes to remove the remaining chromium in treated WBL. Collagenic material was filtered by Whatman- 40 filter paper and washed with distilled water. The nitrogenous collagenic material in now ready to use as a nutrient source of organic fertilizer (Lima et al., 2010). A small amount of WBL and collagen was digested with concentrated acid to convert into the liquid phase for chromium detection by flame analysis method of atomic absorption spectrophotometer (ICE 3000 Series, Thermo Scientific). 
International Journal of Mathematical, Engineering and Management Sciences

Vol. 5, No. 3, 395-404, 2020

https://doi.org/10.33889/IJMEMS.2020.5.3.033

\subsection{Preparation of Organic Fertilizer (Type I)}

Pre-collected water hyacinth leaves were kept under the sunlight to dry completely, and those were converted into powder form by mixer grinder. Then, the water hyacinth powder was burned in the muffle furnace at $450^{\circ} \mathrm{C}$ temperature for 20 minutes. Another ingredient RHA crushed with mortar pestle to get fine ash. The nitrogenous collagenic material, potassium-riched water hyacinth ash (WHA), RHA, and phosphorus-containing commercial steamed bone meal were uniformly mixed with a spatula in a plastic beaker for developing organic fertilizer (Type I). Then, after mixing of organic materials, formulated organic fertilizer was dried and crushed for equal and easy distribution to the field.

\subsubsection{Characterization of Prepared Organic Fertilizer}

Scanning electron microscope (CARL ZEISS MICROSCOPY LTD, EVO - SEM MA15 / 18) was used to study the morphology of the organic fertilizer. Distribution of nutritional elements like nitrogen, phosphorus, potassium present in the prepared organic fertilizer was characterized by energy dispersive x-ray spectroscopy (51N1000 - EDS System, Oxford Instruments Nanoanalysis). Fourier-transform infrared spectroscopy (FTIR) was performed to detect the functional group present in prepared material.

\subsection{Plant growth study on Marigold Plant by Pot Experiment}

The plant growth study was performed to assess the effectivity of the formulated organic fertilizer to release macro and micronutrients to the marigold plant for increasing growth (Nogueira et al., 2011). In addition, the performing ability of the prepared organic fertilizer was justified with commercial N-P-K (10:26:26) fertilizer and vermicompost (Type II fertilizer) applied to check its overall growth onto Marigold plant growth and in terms of height leaf size of the plant. The experiments were performed in four different pots along with $2 \mathrm{~kg}$ of soil on every single pot where $2 \mathrm{gm}$ of commercial fertilizer applied on pot-I, $4 \mathrm{gm}$ of organic fertilizer (Type I fertilizer) on potII, $4 \mathrm{gm}$ of vermicompost (Type II fertilizer) on pot-III, and pot-IV kept without any fertilizer (control). The growth of potted plants in terms of height and leaf size were documented till 36 days of experimentation.

\subsection{Preparation of Liquid Sample of Fertilized Soil for Ammonia Analysis}

After 30 days of the plant growth examination, $5 \mathrm{gm}$ of soil sample was taken from every single pot and individually, samples were added into the $50 \mathrm{ml}$ of deionized water. It was continuously agitated by shaker incubator for five days for leaching (Nogueira et al., 2011) to liberate ammonia from soil samples. Ammonia analyzer was used to calculate the amount of liberated ammonia from prepared liquid samples.

\section{Results and Discussions}

\subsection{Chromium Extraction from WBL}

Atomic absorption spectrophotometry was performed to measure chromium content of the digested WBL and collagen (after treatment) samples. The chromium content of the sample (before treatment) was $12600 \mathrm{mg} / \mathrm{kg}$ of WBL and after treatment the chromium content was observed 2820 $\mathrm{mg} / \mathrm{kg}$. Therefore, the treatment process removed $77.60 \%$ chromium from WBL. The SEM image (Figure 1) clearly visualized the fibers like structure with limited disorientation of this material is due to presence of chromium in the wet blue leather (Abebaw and Abate, 2018). The SEM image of collagenic material (Figure 2) revealed the absence of fibrous aspect and changed into dense nature due to exclusion of chromium is observed as D.Q.L.d. Oliveira et al. reported (D. Q. L. d. 
Oliveira et al., 2008). The comparison between both SEM image reveals that the morphology has been totally changed after chromium removal from WBL (Nogueira et al., 2010).

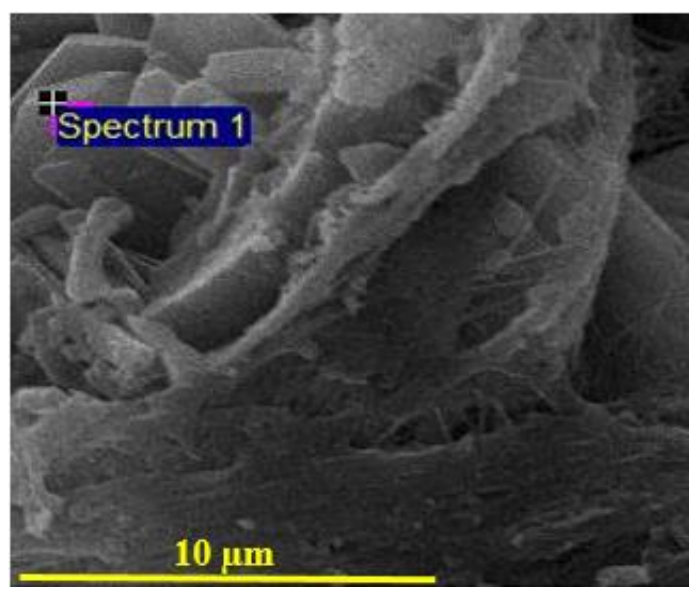

Figure 1. Scanning electron microscopic image of wet blue leather (before chromium removal)

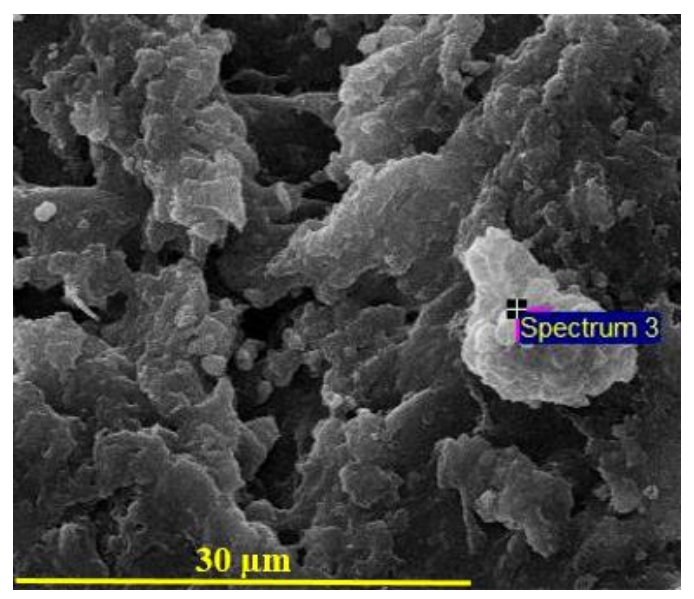

Figure 2. Scanning electron microscopic image of collagenic material (after chromium removal)

\subsection{Characterization of Developed Organic Fertilizer}

The surface morphology of collagenic material and formulated organic fertilizer was investigated by scanning electron microscope. As the steamed bone meal, RHA and WHA amalgamated with collagen, formulated organic fertilizer (Figure 3) appeared as a new type of texture with some small solid structure, and it confirmed the presence of bone meal particles. The closely compacted structure of the collagen was transformed into porous nature, most probably due incorporation of ash (RHA and WHA) into the collagenic material. Porous nature and small solid structure view of the prepared material suggesting the uniform mixing of ingredients. EDS spectra revealed that all major elements were present into the formulated organic fertilizer depicted in Figure 4. The analysis indicated that the weight percentage of different elements like nitrogen, phosphorus, potassium, 
International Journal of Mathematical, Engineering and Management Sciences

Vol. 5, No. 3, 395-404, 2020

https://doi.org/10.33889/IJMEMS.2020.5.3.033

and calcium are $34,1.25,2.4$, and 8.3 , respectively. This result suggested that this fertilizer is a good source of nutrition which can promote the growth of the plant.

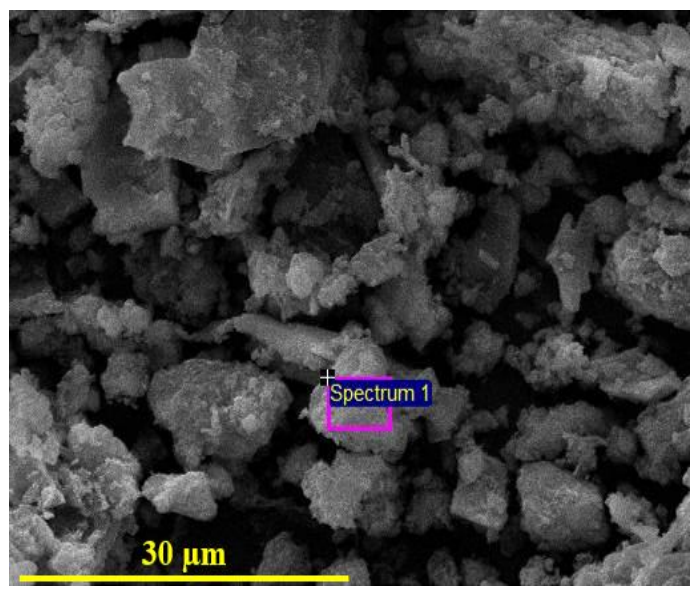

Figure 3. Scanning electron microscopic image of developed organic fertilizer

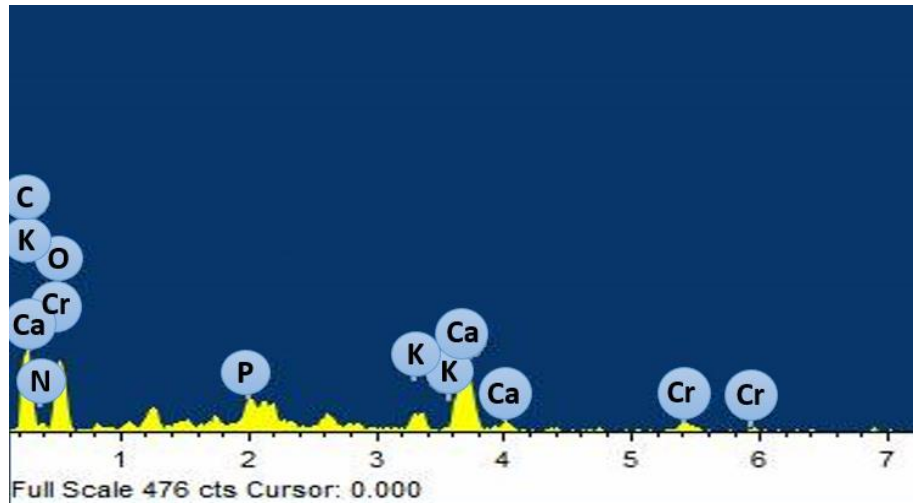

Figure 4. Energy dispersive x-ray spectroscopy graph of formulated organic fertilizer

\subsection{FTIR Investigation of Formulated Organic Fertilizer}

The FTIR spectrum of formulated organic fertilizer was reported in Figure 5. The peak at 3300 $\mathrm{cm}^{-1}$ exposing a wide and strong absorption band, this can be related to the hydroxyl $(\mathrm{OH})$ and amine (NH) group (Domínguez et al., 2006). The small peak with a low-intensity band at 2345 $\mathrm{cm}^{-1}$ corresponding with the $\mathrm{N}-\mathrm{H}$ stretching of an amine group (Sulaiman et al., 2010). The signal at $1658 \mathrm{~cm}^{-1}$ respecting to $\mathrm{C}=\mathrm{O}$ bond of the carboxylic group (Gerzabek et al., 2006; D. Q. L. d. Oliveira et al., 2008) and the band at $1450 \mathrm{~cm}^{-1}$ revealing the deep and long peak which corresponding to $\mathrm{CH}$ and $\mathrm{NH}$ (amide II) groups, are related to the presence of proteins in the peak, which organic fertilizer (Bailey et al., 1998). Medium intensity peak appeared at $1050 \mathrm{~cm}^{-1}$ is associated with the $\mathrm{PO}_{4}{ }^{3-}$ v3 antisymmetric stretching confirming the existence of phosphate molecules (probably from the bone meal) in the developed NPK fertilizer (Farmer, 1974). A sharp and intense peak at $870 \mathrm{~cm}^{-1}$ relating to the carbonate $\left(\mathrm{CO}_{3}{ }^{-2}\right)$ group (Smidt et al., 2002). The short peak at $586 \mathrm{~cm}^{-1}$ associated with the alkyl halide group signifying the presence of chlorine into the WBL waste (Rajeshkumar et al., 2013). 


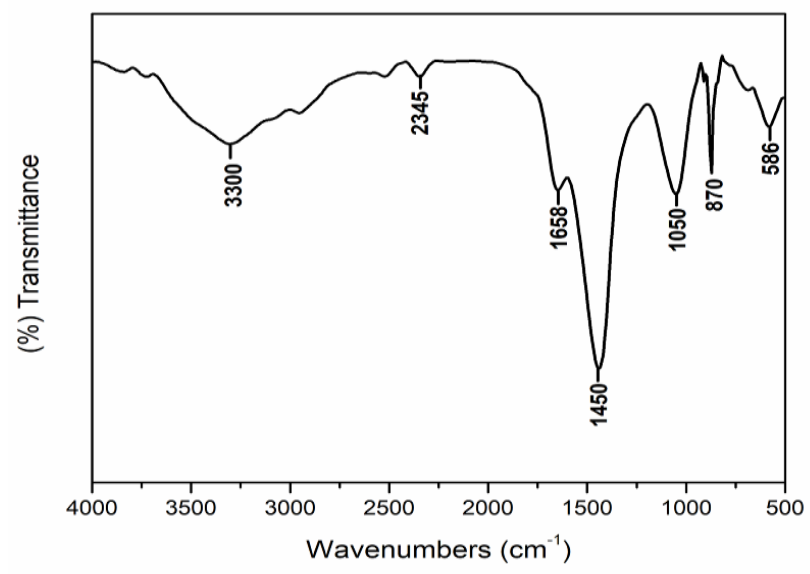

Figure 5. FTIR analysis of formulated organic fertilizer

\subsection{Ammonia Analysis of Prepared Liquid Samples}

The liberated free ammonia from prepared liquid samples of developed organic fertilizer (Type I), vermicompost (Type II), commercial fertilizer, and control were analyzed by ammonia analyzer. As observed from Figure 6, the prepared liquid sample of developed organic fertilizer and vermicompost showed a significant result of free ammonia liberation as $2.9 \mathrm{ppm}$ and $2.6 \mathrm{ppm}$ respectively. But, the chemical fertilizer showed $2.3 \mathrm{ppm}$ at low concentration of liberated ammonia than developed organic fertilizer and vermicompost. Whereas control was showed 1.6 $\mathrm{ppm}$ of free ammonia. Here, free ammonia liberation from the prepared liquid sample of developed organic fertilizer was $44.80 \%, 20.70 \%$, and $10.35 \%$ more than control and the samples of chemical fertilizer (10:26:26) and vermicompost respectively. This analysis proved that a huge quantity of nitrogen was present in developed organic fertilizer which was liberated from it. In the pot experiment, the marigold plant was used liberated ammonia (nitrogen) as a nutrient source from developed organic fertilizer. Due to this reason, the plant growth in terms of height and leaf size was better than the control plant (Lima et al., 2010).

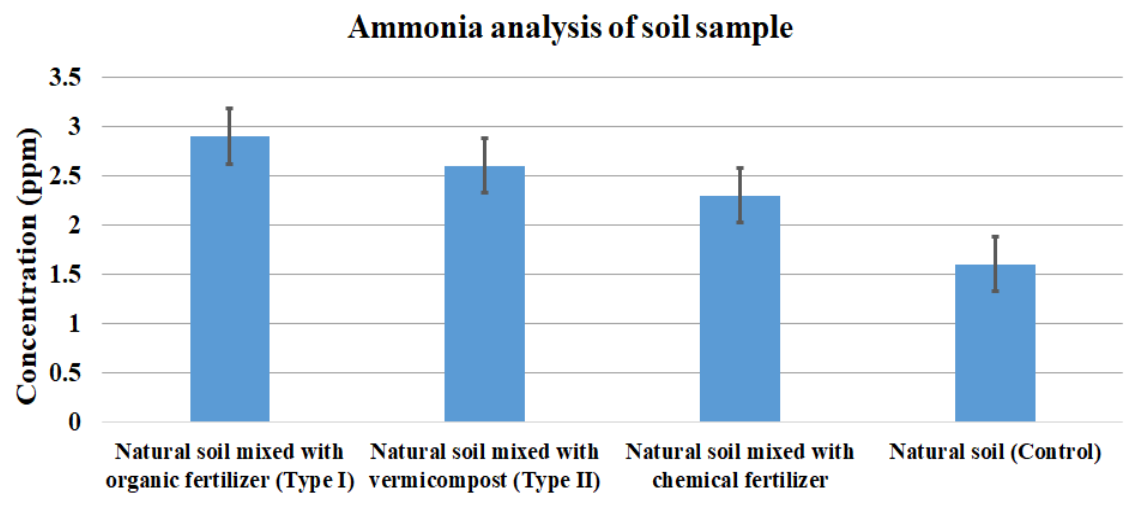

Figure 6. Ammonia analysis for prepared liquid sample of fertilized soil 
International Journal of Mathematical, Engineering and Management Sciences

Vol. 5, No. 3, 395-404, 2020

https://doi.org/10.33889/IJMEMS.2020.5.3.033

\subsection{Observation of Plant Growth}

Four marigold plants were potted with chemical fertilizer, Type I fertilizer (Lab made), Type II fertilizer (vermicompost), and one was kept as control (without fertilizer) respectively. All the experimental and control set of the marigold plants was placed in the open atmosphere under sun rays and water was sprayed in a regular interval. With regular intervals, the growth of the plant in terms of plant height and leaf size, etc. was examined with respect to the control set (Table 1). After Seven days, chemical fertilizer showed maximum response, increased the height of the plant about $15 \%$ and leaf size $10.50 \%$ greater than the control plant but type I and type II organic fertilizer showed plant growth in terms of plant height $5 \%, 7 \%$ and leaf size $2.8 \%, 5 \%$, respectively. Similarly, on the day of 15 , the percentage increased by chemical fertilizer, Type I and Type II was showed plant height about 19.3, 7, 12.2 and leaf size 16.3, 9.3, 11.6 respectively. After 25 days chemical fertilizer, Type I fertilizer and Type II showed percentage increase of plant height 23.4, $13.9,17.1$ and leaf size $20.8,14.6,16.5$ respectively than control plant. Due to the fast-nutrients release, chemical fertilizer showed the maximum effectivity in plant growth for the 1st 25 days. But after that, the organic fertilizer type II (Vermicompost) showed the maximum plant growth indicting its slow release tendency and long-time exposure (Nogueira et al., 2011; Sharma and Mittra, 1991). The details results presented in Figures 7 and Figure 8. Due to control liberation of macro and micro (N, P, K, Ca) nutrients from organic fertilizer Type I showed a better result than chemical fertilizer at 35 days in this study. The effect of chemical fertilizer, Type I fertilizer, Type II fertilizer enhance the growth percentage in terms of plant height by 26.5, 20, 22.7 and leaf size $21.2,15.4,17.3$ greater than the growth of the control plant. Pot experiment demonstrates that type I and type II can be used as an alternative to NPK chemical fertilizer. Developed organic fertilizer (Type I) and vermicompost fertilizer (Type II) as a source of nutrients for the growth of the marigold plant, showed promising agronomic results.

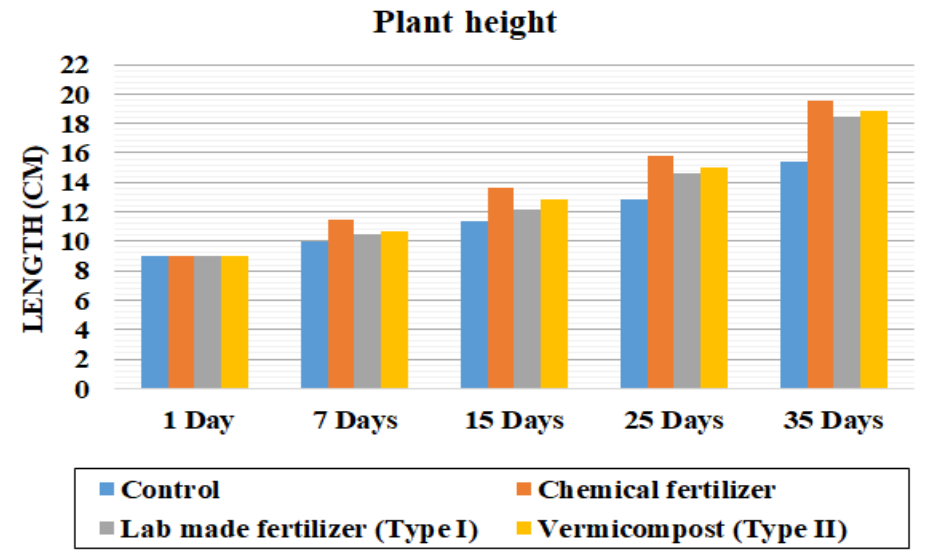

Figure 7. Effect of by different fertilizer on plant growth in terms of plant height 
International Journal of Mathematical, Engineering and Management Sciences

Vol. 5, No. 3, 395-404, 2020

https://doi.org/10.33889/IJMEMS.2020.5.3.033

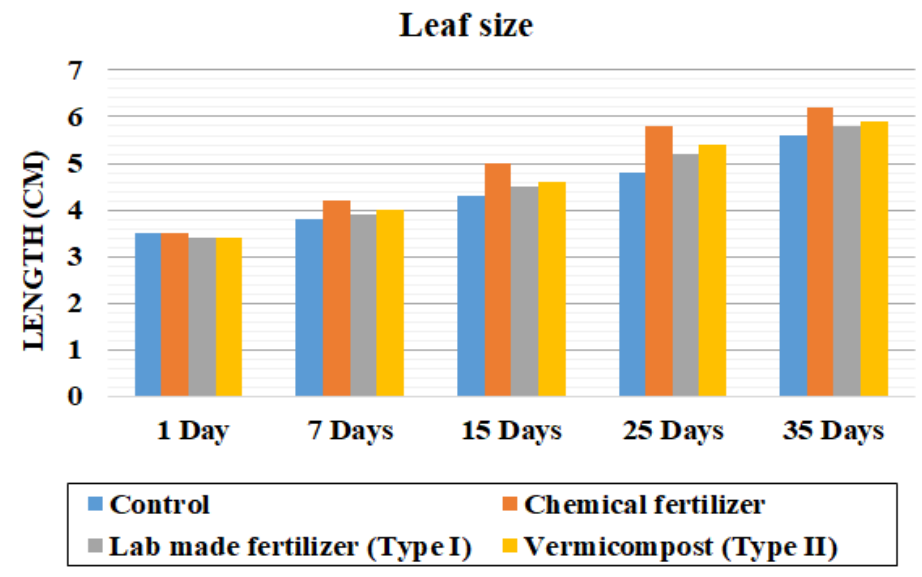

Figure 8 . Effect of by different fertilizer on plant growth in terms of leaf size

Table 1. Observation of plant growth (height) by different fertilizer

\begin{tabular}{|c|c|c|c|c|}
\hline Time & Control $(\mathrm{cm})$ & Chemical fertilizer $(\mathrm{cm})$ & Type I fertilizer $(\mathrm{cm})$ & Type II fertilizer $(\mathrm{cm})$ \\
\hline 1 Day & 9 & 9 & 9 & 9 \\
\hline 7 Days & 10 & 11.5 & 10.5 & 10.7 \\
\hline 15 Days & 11.4 & 13.6 & 12.2 & 12.8 \\
\hline 25 Days & 12.8 & 15.8 & 14.6 & 15 \\
\hline 35 Days & 15.4 & 19.5 & 18.5 & 18.9 \\
\hline
\end{tabular}

\section{Total Area of Cultivatable Land Using This Organic Fertilizer}

Total wet blue leather (WBL) waste generation/ year = 1500000 ton in India.

Total chromium recovery from WBL waste $=45000$ ton (approximately).

Amount of nitrogenous material after chromium removal $(1500000-45000)=1455000$ ton is available to be used for organic fertilizer.

From 1455000 ton nitrogenous material can be produce 6730000 ton of organic fertilizer (according to organic fertilizer formulation).

The total organic fertilizer can be used for crop production $=$ $\left(\frac{6730000 \times 100 \times 1000}{4 \mathrm{~kg} / \mathrm{cm}^{2}}\right) \mathrm{kg}=16825 \times 10^{7} \mathrm{~cm}^{2}=1682.5 \mathrm{ha}$.

Therefore the leather industrial waste in combination with other waste materials will be act as a good fertilizer to cultivate 1682.5 hector land in our country. Moreover this fertilizer is capable to reduce the water consumption of the crops and release the NPK nutrients in a control way. So, that 
International Journal of Mathematical, Engineering and Management Sciences

Vol. 5, No. 3, 395-404, 2020

https://doi.org/10.33889/IJMEMS.2020.5.3.033

eutrophication will be under control and will be safe the natural water body for other unwanted microbial growth in water body.

The land can be covered is $\left(\frac{1682.5}{179721000}\right) \times 100=0.00093617 \%$ of cultivatable land in India.

More optimistically, we may conclude that the developed fertilizer can be used for major portion of cultivatable land in India.

\section{Conclusion}

The present study demonstrated that the developed organic fertilizer type I was prepared by using nitrogen, phosphorus and potassium enriched organic source materials. The plant growth study revealed that the organic fertilizer type I and II, both were showing their efficacies in plant growth and thus could be utilized for replacing chemical fertilizer as it exposed the promising agronomic result. The cost of organic fertilizer production in the study is lower than the chemical fertilizer as it produced from industrial and agricultural waste. This fertilizer is a conversion of industrial and agricultural waste to an eco-friendly and velorized product. After the suitable treatment process, recycling of solid waste materials can accomplish the requirements of macro and micronutrients to the plant as well as diminish hazardous problems related to humans and the environment.

\section{Conflict of Interest}

The authors declare that there is no conflicts of interest associated with this publication.

\section{Acknowledgments}

Authors express their sincere thanks to the Department of Science and Technology, Government of India (SR/FST/ET1405/2015(C)/NITDURGAPUR) for the financial assistance towards necessary instrumental facilities.

\section{References}

Abebaw, G., \& Abate, B. (2018). Chrome tanned leather waste dechroming optimization for potential poultry feed additive source: a waste to resources approach of feed for future. Journal of Environmental Pollution and Management, 1(1), 1-6.

Bailey, A.J., Paul, R.G., \& Knott, L. (1998). Mechanisms of maturation and ageing of collagen. Mechanisms of Ageing and Development, 106(1-2), 1-56.

Domínguez, A., Menéndez, J.A, Inguanzo, M., \& Pis, J.J. (2006). Production of bio-fuels by high temperature pyrolysis of sewage sludge using conventional and microwave heating. Bioresource Technology, 97(10), 1185-1193.

Farmer, V.C. (1974). Infrared spectra of minerals: Mineralogical Society.

Gerzabek, M.H., Antil, R.S., Kögel-Knabner, I., Knicker, H., Kirchmann, H., \& Haberhauer, G. (2006). How are soil use and management reflected by soil organic matter characteristics: a spectroscopic approach. European Journal of Soil Science, 57(4), 485-494.

Han, S.H., An, J.Y., Hwang, J., Kim, S.B., \& Park, B.B. (2016). The effects of organic manure and chemical fertilizer on the growth and nutrient concentrations of yellow poplar (Liriodendron tulipifera Lin.) in a nursery system. Forest Science and Technology, 12(3), 137-143. 
International Journal of Mathematical, Engineering and Management Sciences

Vol. 5, No. 3, 395-404, 2020

https://doi.org/10.33889/IJMEMS.2020.5.3.033

Itelima, J. U., Bang, W. J., Onyimba, I. A., \& Oj, E. (2018). A review: biofertilizer; a key player in enhancing soil fertility and crop productivity. Journal of Microbiology and Biotechnology Reports, 2(1), 22-28.

Kochakinezhad, H., Peyvast, G.-A., Kashi, A.-K., Olfati, J.-A., \& Asadi, A. (2012). A comparison of organic and chemical fertilizers for tomato production. Journal of Organic Systems, 7(2), 14-25.

Lima, D.Q., Oliveira, L.C.A., Bastos, A.R.R., Carvalho, G.S., Marques, J.G.S.M., Carvalho, J.G., \& De Souza, G.A. (2010). Leather industry solid waste as nitrogen source for growth of common bean plants. Applied and Environmental Soil Science, 2010. DOI:10.1155/2010/703842.

Masaka, J., \& Ndhlovu, S. (2007). The Effect of Different Forms of Water Hyacinth (Eichhornia crassipes) Organic Fertilizers on Leaf Growth Rate and Yield of Rape (Brassica napus). International Journal of Agricultural Research, 2(3), 254-260.

Nimje, B.H., \& Potkile, S.N. (1997). Biochemical studies in soybean as influenced by different sources and levels of phosphorus. Journal of Phytological Research, 10(1-2), 103-105.

Nogueira, F.G., Castro, I.A., Bastos, A.R., Souza, G.A., de Carvalho, J.G., \& Oliveira, L.C. (2011). Recycling of solid waste rich in organic nitrogen from leather industry: mineral nutrition of rice plants. Journal of Hazardous Materials, 186(2-3), 1064-1069.

Nogueira, F.G., do Prado, N.T., Oliveira, L.C., Bastos, A.R., Lopes, J.H., \& de Carvalho, J.G. (2010). Incorporation of mineral phosphorus and potassium on leather waste (collagen): a new Ncollagen PKfertilizer with slow liberation. Journal of Hazardous Materials, 176(1-3), 374-380.

Oliveira, D.Q.L.d., Carvalho, K.T.G., Bastos, A.R.R., Oliveira, L.C.A.d., Marques, J.J.G.d.S., \& Nascimento, R.S.d.M.P. (2008). Use of leather industry residues as nitrogen sources for elephantgrass. Revista Brasileira de Ciência do Solo, 32(1), 417-424.

Oliveira, L.C., Goncalves, M., Oliveira, D.Q., Guerreiro, M.C., Guilherme, L.R., \& Dallago, R.M. (2007). Solid waste from leather industry as adsorbent of organic dyes in aqueous-medium. Journal of Hazardous Materials, 141(1), 344-347.

Pode, R. (2016). Potential applications of rice husk ash waste from rice husk biomass power plant. Renewable and Sustainable Energy Reviews, 53, 1468-1485.

Priyadharshini, J., \& Seran, T.H. (2009). Paddy husk ash as a source of potassium for growth and yield of cowpea (Vigna unguiculata L.). The Journal of Agricultural Sciences, 4(2), 67-76.

Rajeshkumar, S., Malarkodi, C., Gnanajobitha, G., Paulkumar, K., Vanaja, M., Kannan, C., \& Annadurai, G. (2013). Seaweed-mediated synthesis of gold nanoparticles using Turbinaria conoides and its characterization. Journal of Nanostructure in Chemistry, 3(1), 44.

Sharma, A.R., \& Mittra, B.N. (1991). Effect of different rates of application of organic and nitrogen fertilizers in a rice-based cropping system. The Journal of Agricultural Science, 117(3), 313-318.

Shimbo, S., Zhang, Z.-W., Watanabe, T., Nakatsuka, H., Matsuda-Inoguchi, N., Higashikawa, K., \& Ikeda, M. (2001). Cadmium and lead contents in rice and other cereal products in Japan in 1998-2000. Science of the Total Environment, 281(1-3), 165-175.

Smidt, E., Lechner, P., Schwanninger, M., Haberhauer, G., \& Gerzabek, M.H. (2002). Characterization of waste organic matter by FT-IR spectroscopy: application in waste science. Applied Spectroscopy, 56(9), $1170-1175$.

Sulaiman, O., Amini, M.H.M., Rafatullah, M., Hashim, R., \& Ahmad, A. (2010). Adsorption equilibrium and thermodynamic studies of copper (II) ions from aqueous solutions by oil palm leaves International Journal of Chemical Reactor Engineering , 8(1), 1-16. https://doi.org/10.2202/1542-6580.2350. 